\title{
Effect of aging on anorectal function
}

\author{
J J BANNISTER, L ABOUZEKRY, AND N W READ \\ From the Department of Surgery, Royal Hallamshire Hospital, Sheffield and Tickhill Road Hospital, \\ Doncaster
}

SUMmARY Measurements of anorectal function were conducted on 37 elderly (66-87 years) and 48 young (19-55 years) normal subjects. Elderly subjects had decreased anal pressures compared with younger subjects, required lower rectal volumes to inhibit anal sphincter tone and had increased rectal pressures upon balloon distension. The rectal volume required to cause the desire to defecate and the maximum tolerated volume were lower in the elderly, but the corresponding rectal pressures were similar, indicating the sensations were mediated by tension, or pressure receptors. Rectal contractions were generated at similar degrees of rectal distension. A lower proportion of elderly, compared with young subjects could defecate a sphere $18 \mathrm{~mm}$ in diameter within 20 seconds. The degree of perineal descent was greater in the elderly female subjects compared with the young women, although there was no difference in this measurement between men. The anorectal angle was similar in young and old. The changes in anorectal function in the elderly would tend to make them more susceptible to faecal incontinence.

\begin{abstract}
Although faecal incontinence' and constipation² are common accompaniments of old age, the changes in anorectal physiology due to aging are scantily documented. Read et al and Matheson and Keighley showed that maximum basal and squeeze pressures in the anal canal were significantly lower in older subjects than in younger subjects. Electrophysiological techniques have shown that elderly people have a greater degree of neuropathic damage to the external anal sphincter. "Ihre" showed that a group of older women aged 52 to 69 years had higher rectal pressures for any given distending volume than a group of younger women, aged between 19 and 44 years, and could not tolerate as high a rectal volume. Devroede et al, however, was unable to show any effect of aging on rectal compliance in a group of 47 healthy controls aged between 42 and 77 years. The aim of this study was to document the results of a comprehensive series of tests of anorectal function in young and elderly normal subjects.
\end{abstract}

Address for correspondence: Dr N W Read. Subdepartment of lluman (iastrointestinal Physiology and Nutrition. K Floor. Royal Hallamshire Hospital. Shefficld SIO 2JF.

Received for publication 11 July 1986 .
Methods
SUBJECTS
Studies were carried out in 37 elderly subjects (17
men and 20 women) aged between 66 and 87 years
(mean \pm SEM; $78 \pm 1$ year) and 48 younger volunteers
(21 men and 27 women) aged between 19 and 55
years (mean \pm SEM; $32 \pm 2$ years). None of these
subjects had any difficulty with defecation or any
abdominal complaints.
The elderly subjects were taking more medication
than the young. Six of the elderly were taking drugs
known to affect the gastrointestinal system; these
included tricyclic antidepressants, dextropropoxy-
phene and non-steroidal anti-inflammatory drugs.
The elderly also had a higher incidence of chronic
illness including arthritis, cerebrovascular episodes,
neoplasia, and bronchitis. No subject in either group
had undergone perianal surgery, or received medica-
tion to alter their bowel habit.
All subjects gave informed consent and the study
was approved by the Sheffield and Doncaster Area
Ethical Committees in October, 1981 .
All subjects underwent a series of investigations,
which included anorectal manometry and radiology,
tests of rectal sensation and tests of their ability to
pass a simulated stool. No bowel preparation was 
used before testing apart from offering the subjects the opportunity to defecate. None of the elderly patients had a rectum full of faeces at the time the tests were carried out.

\section{ANORECTAI. MANOMETRY \\ Anal sphincter pressures}

Maximum basal and maximum squeeze pressures in the anal canal were measured using a station pullthrough technique using three low compliance water perfused catheters (external diameter $1.5 \mathrm{~mm}$ ) bonded together so that their distal side openings were situated $2.5 \mathrm{~cm}$ apart and orientated to sample points $120^{\circ}$ apart.

\section{Anal responses to rectal distension}

Anal pressures were recorded during serial inflation of a rectal balloon with increasing volumes of air." Rectal volumes were increased until the balloon was spontaneously expelled, or until anal tone failed to recover while the balloon remained inflated. The presence or absence of sphincter relaxation or contraction was noted, as well as the lowest rectal volume required to elicit a transient relaxation and the lowest volume that induced sustained relaxation of the anal sphincter for the duration of the distension.

\section{Distension of a rectal balloon with air}

Rectal pressure was recorded during distension of a cylindrical rectal balloon with $50 \mathrm{ml}$ increments of air," allowing one minute for the trace to stabilise to each new volume. When the rectal balloon was distended, there was a sudden sharp rise in pressure caused by introducing the air. This was followed by a phasic increase in pressure, probably because of a rectal contraction, and a slow fall to the steady state rectal pressure for that volume. Steady state rectal pressure was calculated by subtracting the pressure measured during inflation of the balloon outside the patient from the pressure recorded with the balloon in the rectum using the same inflation volume. The subject was also asked if he could perceive the balloon, felt a desire to defecate or felt pain at each distending volume.

TESTS OF EXPULSION OF SIMULATED STOOIS These tests were designed to evaluate the ability of subjects to pass a water filled balloon or a small plastic sphere which were placed in the rectum." A

Table Anorectal function in young and old subjects

\begin{tabular}{|c|c|c|c|c|c|c|c|c|c|}
\hline \multirow[t]{2}{*}{ Test } & \multicolumn{3}{|l|}{ Male } & \multicolumn{3}{|l|}{ Female } & \multicolumn{3}{|c|}{ Total (male + female) } \\
\hline & Young & Old & $p$ & Young & Old & $p$ & Young & Old & $p$ \\
\hline \multicolumn{10}{|l|}{ Anal pressures $\left(\mathrm{cmH}_{2} \mathrm{O}\right)$} \\
\hline Mean highest basal & 10()$\cdot() \pm 5$ & $73 \cdot() \pm 7$ & $<0 \cdot() 1$ & $103 \cdot() \pm 8$ & $57 \cdot() \pm 4$ & $<() \cdot()(0) 1$ & $102 \cdot 0 \pm 5$ & $6.5 \cdot() \pm 4$ & $<0 \cdot()() 1$ \\
\hline Mean highest squecze & $284 \cdot() \pm 20$ & $214 \cdot() \pm 23$ & $<0 \cdot(05$ & $217 \cdot 0 \pm 16$ & $132 \cdot() \pm 9$ & $<0 \cdot()() 1$ & $247 \cdot() \pm 14$ & $171 \cdot() \pm 15$ & $<() \cdot()() 1$ \\
\hline \multicolumn{10}{|c|}{ Anal response to rectal distension } \\
\hline $\begin{array}{l}\text { Rectal volume required to } \\
\text { cause anal relaxation ( } \mathrm{mls} \text { ) }\end{array}$ & $23 \cdot() \pm 3$ & $29 \cdot() \pm 8$ & NS & $21 \cdot() \pm 2$ & $23 \cdot(1 \pm 4$ & NS & $22 \cdot(1 \pm 2$ & $26 \cdot() \pm 4$ & NS \\
\hline $\begin{array}{l}\text { Rectal volume required to } \\
\text { cause sustained anal } \\
\text { relaxation (mls) }\end{array}$ & $74 \cdot 0 \pm 9$ & $48 \cdot 0 \pm 9$ & NS & 6()$\cdot() \pm 7$ & $39 \cdot(1 \pm 7$ & $<0 \cdot(05$ & $69 \cdot(1 \pm 6$ & $42 \cdot() \pm 5$ & $<() \cdot(05$ \\
\hline \multicolumn{10}{|c|}{$\begin{array}{l}\text { Rectal pressures and volumes }\left(\mathrm{cmH}_{2} \mathrm{O}\right) \\
\text { Distending volume }(\mathrm{ml})^{*}\end{array}$} \\
\hline 50 & $15 \cdot 7 \pm 2 \cdot 3$ & $18 \cdot 3 \pm 2 \cdot 8$ & NS & $11 \cdot 9 \pm 0 \cdot 8$ & $25 \cdot 1 \pm 2 \cdot 6$ & $<() \cdot())$ & $13 \cdot 4 \pm 1 \cdot()$ & $21 \cdot 4 \pm 2 \cdot 1$ & $<() \cdot() 1$ \\
\hline 150 & $27 \cdot 2 \pm 4 \cdot 2$ & $31 \cdot 0 \pm 3 \cdot 8$ & NS & $20 \cdot 5 \pm 1 \cdot 7$ & $32 \cdot 6 \pm 3 \cdot 4$ & $<() \cdot() 1$ & $23 \cdot 1 \pm 2 \cdot()$ & $31 \cdot 8 \pm 2 \cdot 5$ & $<(1) \cdot())$ \\
\hline $\begin{array}{l}\text { Maximum tolerable volume } \\
(\mathrm{ml})\end{array}$ & $265 \cdot() \pm 20$ & $209 \cdot 0 \pm 19$ & NS & $297 \cdot 0 \pm 19$ & $250 \cdot() \pm 17$ & NS & $283 \cdot(1 \pm 14$ & $225 \cdot() \pm 13$ & $<() \cdot())$ \\
\hline $\begin{array}{l}\text { Maximum tolerable pressure } \\
\text { (cm water) }\end{array}$ & $46 \cdot() \pm 6$ & $35 \cdot() \pm 4$ & NS & $38 \cdot(1 \pm 4$ & $47 \cdot(1 \pm 4$ & NS & $41 \cdot(1 \pm 4$ & $41 \cdot 0 \pm 3$ & NS \\
\hline \multicolumn{10}{|l|}{$\begin{array}{l}\text { Radiographic measurements } \\
\text { Anorectal angle (degrees) }\end{array}$} \\
\hline At rest & $91 \cdot 0 \pm 1$ & $95 \cdot() \pm 4$ & NS & $88 \cdot() \pm 3$ & $\varphi() \pm 3$ & NS & $89 \cdot(1 \pm 2$ & $92 \pm 2$ & NS \\
\hline Straining & $105 \cdot 0 \pm 8$ & $111 \cdot 0 \pm 5$ & NS & $115 \cdot 0 \pm 7$ & $98 \cdot(1 \pm 4$ & $<0 \cdot() 5$ & $112 \cdot 0 \pm 5$ & $104 \cdot() \pm 4$ & NS \\
\hline \multicolumn{10}{|c|}{ Distance of anorectal angle from pubococcygeal linc $(\mathrm{cm}) \dagger$} \\
\hline At rest & $+(0 \cdot 1 \pm() \cdot 1$ & $-0.2 \pm() \cdot 4$ & NS & $0 \cdot() \pm() \cdot 3$ & $-1 \cdot 5 \pm(0 \cdot 3$ & $<() \cdot() 1$ & $(0 \cdot 0 \pm(0 \cdot 2$ & $-(1) \cdot 8 \pm 0.3$ & NS \\
\hline Straining & $-1 \cdot 8 \pm(1 \cdot 4$ & $-1 \cdot 6 \pm 0 \cdot 6$ & NS & $-1 \cdot 6 \pm 0 \cdot 3$ & $-3 \cdot 6 \pm() \cdot 4$ & $<() \cdot())$ & $-1 \cdot 7 \pm 0 \cdot 2$ & $-2 \cdot 6 \pm 0 \cdot 4$ & NS \\
\hline
\end{tabular}

Results are expressed as mean \pm SEM.

*Values are given only for distending volumes up to $150 \mathrm{ml}$ as some patients could not tolerate distension above that volume:

†Positive values denote distances above and negative values below the pubococcygeal line. 
cylindrical balloon containing $50 \mathrm{ml}$ water simulated a soft stool. A hard plastic solid sphere of diameter 18 $\mathrm{mm}$ resembled the small faecal pellets that many constipated patients produce. Expulsion was carried out while subjects sat on a commode.

ANORECTAL. RADIOLOGY

Lateral radiographs of the anorectal region were carried out in order to measure the anorectal angle and the degree of perineal descent below the pubococcygeal line."'

In young women, the test was always carried out during the first 10 days of the menstrual cycle.

\section{STATISTICAL. ANALYSIS}

The statistical significance of sets of data, that appeared to be normally distributed, was assessed by Student ' $t$ test. The Wilcoxon's rank sum was used to test the significance of data that were not normally distributed. The probability of events which could be expressed in a $2 \times 2$ contingency table was read from tables of standard values."

\section{Results}

DIFFERENCES BETWEEN YOUNG AND ELDERLY SUBJECTS

Anal pressures

The mean highest basal and mean highest squeeze pressures were significantly lower in the elderly subjects compared with the young (Table). These differences were greater for women than men. The values for the mean highest squeeze pressures were significantly higher in both the young and old men compared with the young and old women $(p<0 \cdot 01)$ (Table).

\section{ANAL RESPONSE TO RECTAL DISTENSION}

The rectal volume required to induce relaxation of the anal sphincter in the elderly was similar to that in younger people, though the elderly women required less rectal distension than younger women to cause a sustained relaxation of the anal sphincter (Table). In seven elderly subjects, rectal discomfort or spontaneous expulsion of the balloon caused the test to be stopped before sustained relaxation occurred.

\section{Rectal pressures during rectal distension}

The steady state rectal pressures recorded during distension of a rectal balloon with air were higher in elderly subjects compared with the young and the differences were statistically significant for women and for men and women together (Table). There were no significant differences in the results from male and female subjects in either age range.

There was no significant difference in the rectal volumes or pressures required to give rise to rectal contractions between young and old subjects, or between men and women in each group.

\section{Rectal sensation}

There was no significant difference between the rectal volumes or pressures which could be perceived by elderly and young subjects (Fig. 1). A greater percentage of elderly subjects felt the desire to defecate when the rectal balloon was distended with $50 \mathrm{ml}$ air $(\mathrm{p}<0.01)$ (Fig. 1). When the percentage of patients experiencing the desire to defecate was plotted against rectal pressure, there was no difference between the young and old subjects (Fig. 1).

The maximum tolerable volume was significantly lower in the elderly than the young $(p<0 \cdot 05)$ (Table), although there was no significant difference in the maximum tolerable pressure (Table). There were no significant differences in rectal sensation between men and women in either the young or elderly groups.

\section{Simulated defecation}

A lower percentage of old than young subjects could expel the simulated stools within 20 seconds (Fig. 2) and this achieved statistical significance for the small sphere. All the young subjects and nearly all the elderly subjects could expel the simulated stools within five minutes. There were no differences in the abilities of men and women in each group to expel these simulated stools.

\section{Anorectal angulation}

The anorectal angle at rest was similar in the young and elderly groups, and no differences were shown between men and women subjects in each age range (Table). Upon straining, the anorectal angle was less obtuse in the elderly compared with the young women.

Distance of anorectal angle from pubococcygeal line Elderly female subjects had a significantly greater degree of perineal descent both at rest and upon straining than young women $(p<0 \cdot(01)$ or elderly men $(p<0 \cdot 05)$ (Table). There were no significant differences between the measurements from young and old male subjects or from young men and women.

\section{Discussion}

This study has confirmed that anal pressures are lower in the elderly than in the young. ${ }^{3+}$ The reduction in pressures that occurs with aging is greater in women than men, and greater for squeeze pressure than basal pressure; the maximum squeeze pressure in elderly women is $63 \%$ that in elderly men, whereas 

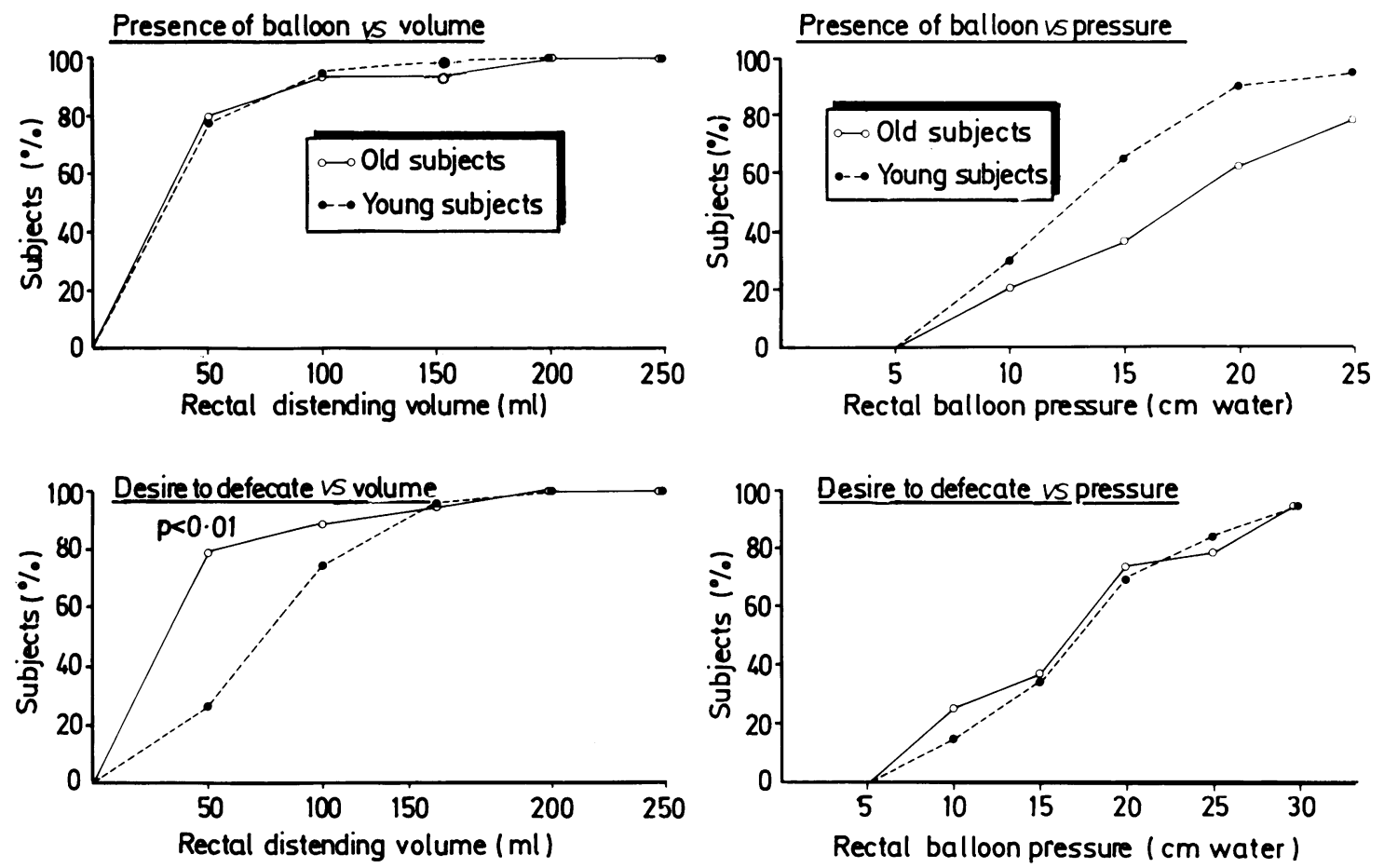

Fig. 1 Percentage of subjects who could perceive a rectal balloon distended with a given volume or pressure (top) and the percentage of subjects, in whom a given volume or pressure in a rectal balloon gave rise to a desire to defecate (bottom).

the maximum squeeze pressure in younger women is $75 \%$ that in younger men. This reduction of sphincter pressures may be due in part to an age related reduction in muscle contractility and bulk and in part to the progressive neuropathic damage to the external anal sphincter that occurs with aging as shown by an increase in the length of the motor unit potentials. 5 The greater reduction in sphincter pressures in elderly women may be explained by damage to the nerve supply to the pelvic floor sustained during childbirth. ${ }^{12}$ This causes descent of the perineum as the subject strains to pass a motion; stretching the pudendal nerve as it winds around the ischial spine, and causing neuropathic weakness of the external anal sphincter. In support of this hypothesis, elderly women have a significantly greater degree of perineal descent than young women, both at rest and on straining, whereas the position of the anorectal angle in relation to the pubococcygeal line is no different in elderly compared with young men.

Perineal descent and a weak sphincter are thought to encourage the anterior rectal mucosa to prolapse and plug the anal canal, obstructing defecation..$^{1311}$ Although our results showed that a lower proportion of elderly subjects than younger subjects could pass simulated stools within 20 seconds, this difference disappeared when the time limit was extended to five minutes. The elderly may therefore strain for longer periods than the young, while attempting to pass a stool, possibly causing damage to the innervation of the pelvic floor. ${ }^{15}$ Elderly women, however, did not experience greater difficulty at defecation than elderly men even though they had significantly more perineal descent. Thus, the degree of perineal descent may not predispose to impaired defecation in the elderly.

Our data support the previous findings of Ihre" that elderly subjects generated higher steady state rectal pressures when a balloon was distended in the rectum. These findings may reflect the generalised

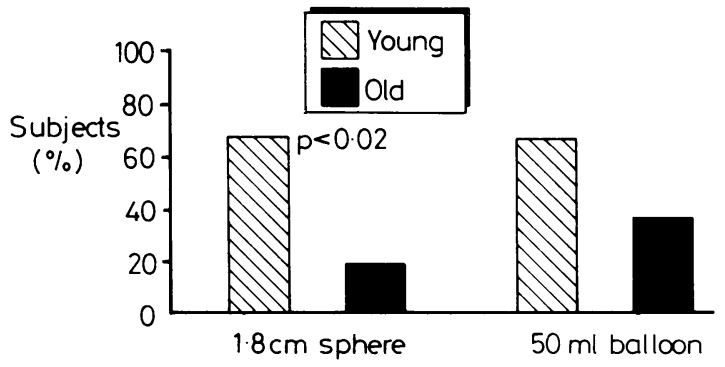

Fig. 2 Percentage of subjects able to pass a $50 \mathrm{ml}$ balloon or an $18 \mathrm{~mm}$ sphere within 20 seconds. 
loss in tissue elasticity that occurs with age or it may result from rectal ischaemia and fibrosis. The changes in rectal pressure were associated with a more sensitive recto-anal inhibitory reflex and with increases in rectal sensitivity; less rectal distension was required to elicit a desire to defecate in the elderly. The difference in this particular sensation disappeared when the rectal pressure was plotted instead of rectal volume, suggesting that a desire to defecate was initiated by stimulation of tension or pressure receptors. This is in contrast with rectal perception which is more closely related to rectal volume than rectal pressure (Fig. 1).

Our results could explain why elderly subjects commonly become more incontinent when their faeces are liquid. Our previous studies" have shown that incontinence to rectally infused saline occurs when the rectal pressure is greater than the anal pressure. The combination of higher rectal pressures upon rectal distension and lower anal pressures and the observation that it takes lower rectal volumes to cause sustained anal relaxation will all increase the risk of incontinence in the elderly group.

\section{References}

1 Brocklehurst JC. Bowel management in the neurologically disabled. The problems in old age. Proc $R$ Soc Med 1972; 65: 66-9.

2 Exton-Smith AN. Constipation in geriatrics. In: Jones AF, Godding FW, eds. Management of constipation. Oxford: Blackwell Scientific Publications, 1972: 156-75.

3 Read NW, Harford WV, Schmulen AC, Read MG, Santa Ana C, Fordtran JS. A clinical study of patients with fecal incontinence and diarrhoea. Gastroenterology 1979; 76: 747-56.

4 Matheson DM, Keighley MRB. Manometric evaluation of rectal prolapse and faecal incontinence. Gut 1981;22: $126-9$.
5 Bartolo DCC, Jarratt JA, Read NW. The use of conventional electromyography to asess external sphincter neuropathy in man. $J$ Neurol Neurosurg Psychiatry 1983; 46: 1115-8.

6 Ihre T. Studies on anal function in continent and incontinent patients. Scand J Gastroenterol 1974; 9 suppl. 25.

7 Devroede G, Vobecky S, Masse S, et al. Ischaemic fecal incontinence and rectal angina. Gastroenterology 1982; 83: 970-80.

8 Read MG, Read NW, Barber DC, Duthie HL. Effect of loperamide on anal sphincter function in patients complaining of chronic diarrhea with fecal incontinence and urgency. Dig Dis Sci 1982; 27: 807-14.

9 Read NW, Timms JM, Barfield LJ, Donnelly TC, Bannister JJ. Impairment of defecation in young women with severe constipation. Gastroenterology 1986; 90: $53-60$.

10) Bartolo DCC, Read NW, Jarratt JA, Read MG, Donnelly TC, Johnson AG. Differences in anal sphincter function and clinical presentation in patients with pelvic floor descent. Gastroenterology 1983; 85: $68-75$.

11 Documenta Geigy. Scientific tables Macclesfield: Geigy Pharmaceuticals, 1970)

12 Snooks SJ. Setchell M. Swash M, Henry MM. Injury to innervation of pelvic floor sphincter musculature in childbirth. Lancet 1984; 2: 546-50.

13 Parks AG, Porter NH, Hardcastle JD. The syndrome of the descending perineum. Proc $R$ Soc Med 1966; 59: 477-82.

14 Hardcastle JD. The descending perineum syndrome. The Practitioner 1969; 203: 612-20.

15 Snooks SJ, Barnes PRH, Swash M, Henry MM. Damage to the innervation of the pelvic floor musculature in constipation. Gastroenterology 1985; 89: 977-81.

16 Read NW, Haynes WG, Bartolo DCC, et al. Use of anorectal manometry during rectal infusion of saline to investigate sphincter function in incontinent patients. Gastroenterology 1983; 85: 105-13. 